\title{
Un caso de exantema fijo medicamentoso causado por diclofenaco y naproxeno
}

\section{A case of generalized bullous fixed drug eruption caused by diclofenac and naproxen}

\section{CASE REPORT}

Fixed drug eruption is an adverse drug effect that characteristically recurs in the same locations upon re-exposure to the offending drug, more frequently non-steroid anti-inflammatory drugs (NSAIDs) and antibiotics ${ }^{1}$. It usually presents with a single or a small number of dusky red or violaceous plaques that resolve, leaving post-inflammatory hyperpigmentation. Generalized bullous fixed drug eruption (GBFDE), is a particular form of fixed drug eruption characterized by widespread blisters and erosions and can be confused with StevensJohnson syndrome and toxic epidermal necrolysis².

We report a case of a 74-year-old woman with medical history of hypertension, lumbar spine osteoarthritis and cutaneous hypersensitivity reaction to diclofenac three years ago, that manifested by erythematous bullous patches over the back, abdomen lower and upper limbs that resolved spontaneously leaving a residual hyperpigmentation. The patient was admitted at the emergency department due to similar erythematous pruriginous plaques of varied sizes, some bullous, over the back, lower and upper limbs, on the same locations of the previous lesions and hard palate, with no other significant findings on clinical evaluation. Those cutaneous lesions appeared about 6 hours after naproxen intake due to back pain. Regarding the recurrence of those lesions with similar pattern distribution, the diagnosis of generalized bullous fixed drug eruption was extremely probable. She initiated treatment with prednisolone and a skin biopsy of a lesion on the left tight was performed after she was admitted on Internal Medicine Ward. The diagnosis was later reassured by histopathologic findings and the patient was discharged and instructed to avoid naproxen, diclofenac and other NSAIDs.

This case highlights the importance of an effective clinical evaluation and medical questionnaire, since GBFDE can mimic serious medical conditions.

\section{REFERENCES}

1. Santra R, Pramanik S, Raychaudhuri P. Fixed Drug Eruption due to Fluconazole: Not so uncommon Now-a-days. J Clin Diagn Res. 2014;8(11):HL01.

2. Cho YT, Lin JW, Chen YC, et al. Generalized bullous fixed drug eruption is distinct from Stevens-Johnson syndrome/toxic epidermal necrolysis by immunohistopathological features. J Am Acad Dermatol. 2014;70(3):539-548.

Palabras clave: exantema fijo medicamentoso, naproxeno, diclofenaco. Keywords: fixed drug eruption, naproxeno, diclofenac.

\section{Sara Freitas, Joana Marques}

'Serviço de Medicina Interna, Hospital Beatriz Ângelo, Loures, Portugal

Correspondencia: saracmfreitas@gmail.com

Cómo citar este artículo: Freitas S, Marques

Un caso de exantema fijo medicamentoso causado por diclofenaco y naproxeno. Galicia Clin 2021; 82-1:64 Recibido: 7/11/2019; Aceptado: 27/11/2019 // https://doi.org/10.22546/60/2143
Fig. 1. Bullous eruption on the hard palate.

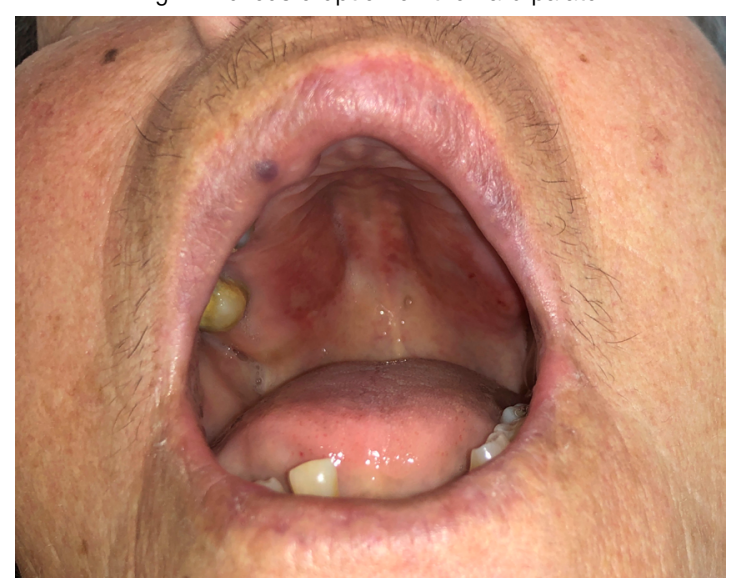

Fig. 2. Bullous eruptions on the left hand and residual hyperpigmentation on the left wrist.

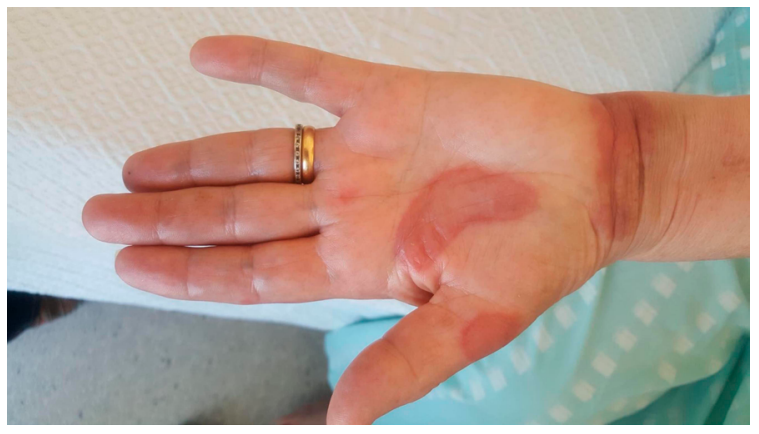

Fig. 3. Dusky patches, with bullae and residual hyperpigmented lesions on the right leg.

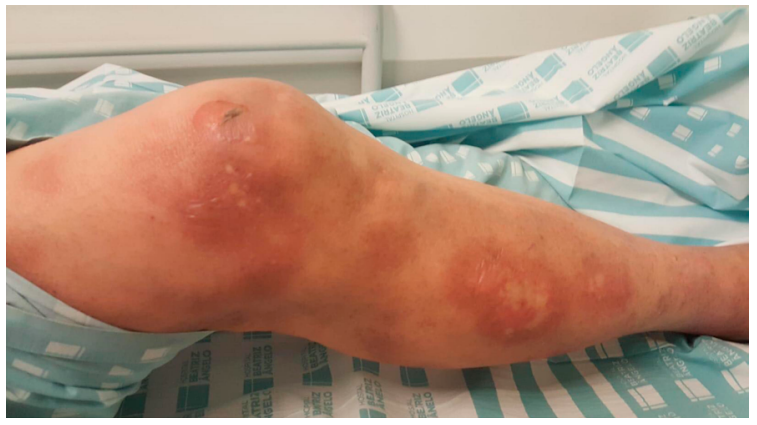

Fig. 4. Erythematoviolaceous, oval macules and patches affecting the abdomen, with residual hyperpigmented lesions with associated skin discoloration.

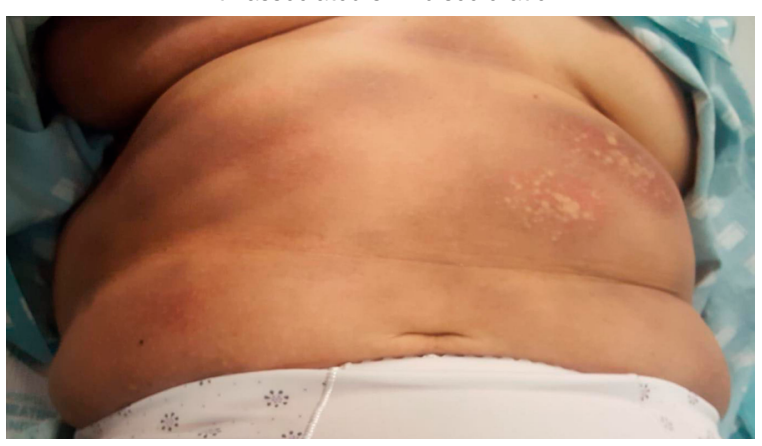

